\title{
LIQUID PHASE METHANOL LAPORTE PROCESS DEVELOPMENT UNIT MODIFICATION, OPERATION, AND SUPPORT STUDIES
}

Topical Report for the Period April 9, 1987-October 9, 1990

Task 3.6/3.7: Alternative Catalyst/Life Run

January 28, 1991

Work Performed Under Contract No. AC22-87PC90005

For

U.S. Department of Energy

Pittsburgh Energy Technology Center

Pittsburgh, Pennsylvania

By

Air Products and Chemicals, Inc.

Allentown, Pennsylvania

and

Chem Systems, Inc.

Tarrytown, New York 


\section{DISCLAIMER}

This report was prepared as an accoun of work sponsored by an agency of the United States Government. Neither the United States Government nor any agency thereof, nor any of their employees, makes any warranty, express or implied, or assumes any legal liability or responsibility for the accuracy, completeness, or usefulness of any information, apparatus, product, or process disclosed, or represents that its use would not infringe privately owned rights. Reference herein to any specific commercial product, process, or service by trade name, trademark, manufacturer, or otherwise does not necessarily constitute or imply its endorsement, recommendation, or favoring by the United States Ciovernment or any agency thereof. The views and opinions of authors ex. pressed herein do not necessarily state or reflect those of the United States Government or any agency thereof.

This report has been reproduced directly from the best available copy.

Available to DOE and DOE contractors from the Office of Scientific and Technical Information, P.O. Box 62, Oak Ridge, TN 37831; prices available from (615)576-8401, FTS 626-8401.

Available to the public from the National Technical Information Service, U.S. Department of Commerce, 5285 Port Royal Rd., Springfield, VA 22161. 
LIQUID PHASE METHANOL LAPORTE PROCESS DEVELOPMENT UNIT MODIFICATION, OPERATION, AND SUPPORT STUDIES

Topical Report

Task 3.6/3.7: Alternative Catalyst/Life Run

Contractor

AIR PRODUCTS AND CHEMICALS, INC.

Allentown, PA 18195

and

CHEM SYSTEMS INC.

Tarrytown, NY 10591

28 January 1991

Prepared for the United States Department of Energy

Under Contract No. DE-AC22-87PC90005

Contract Period 9 April 1987 - 9 October 1990 


\section{Contents}

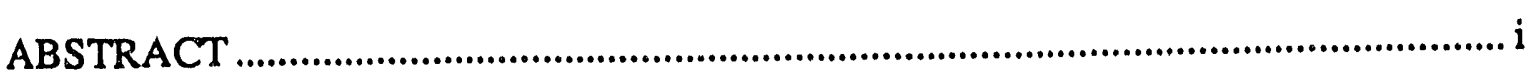

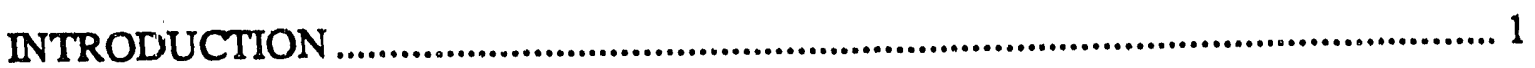

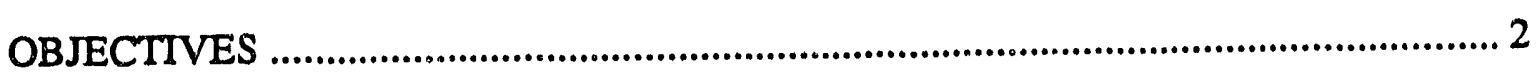

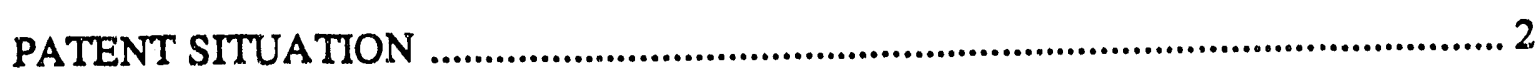

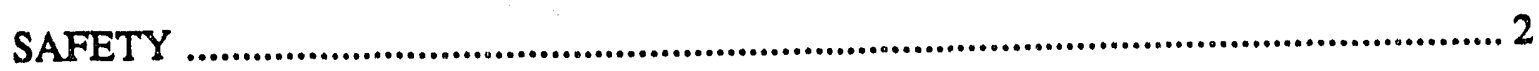

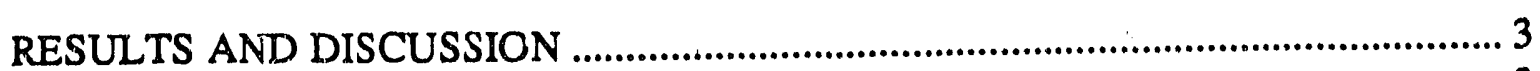

A. Selection of Commercial Catalysts .............................................................. 3

B. Catalyst Activity Test in Lab Autoclave ....................................................... 3

C. Measurement of Slurry Viscosity .............................................................. 4

D. Batch Sedimentation Tests ...................................................................... 4

E. Comparison of Catalyst Properties ............................................................... 8

F. Further Comparison of Properties between F21/0E75-43 and F21/0E75-44 Catalyst ............................................................................. 8

G. Activity Maintenance of Catalyst F21/0E75-43 in Autoclave .......................... 12

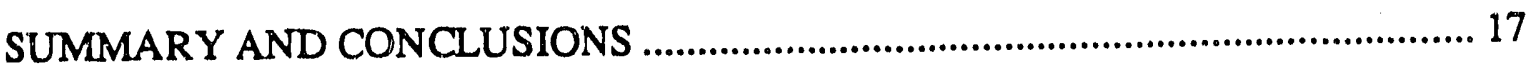

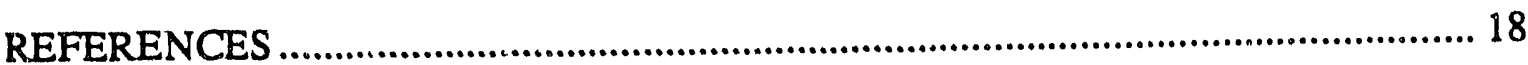

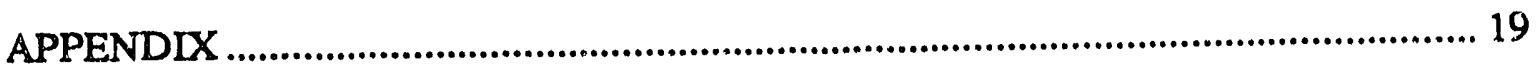




\section{ABSTRACT}

In April 1987, Air Products started the third and final contract with the U.S. Department of Energy to develop the Liquid Phase Methanol (LPMEOH*) process. One of the objectives was to identify alternative commercial catalyst(s) for the process. This objective was strategically important as we want to demonstrate that the LPMEOH process is flexible and not catalyst selection limited.

Among three commercially available catalysts evaluated in the lab, the catalyst with a designation of F21/0E75-43 was the most promising candidate. The initial judging criteria included not only the intrinsic catalyst activity but also the ability to be used effectively in a slurry reactor. The catalyst was then advanced for a 40-day life test in a laboratory $300 \mathrm{cc}$ autoclave. The life test result also revealed superior stability when compared with that of a standard catalyst. Consequently, the new catalyst was recommended for demonstration in the Process Development Unit (PDU) at LaPorte, Texas.

This report details the methodology of testing and selecting the catalyst.

*A trademark. 


\section{INTRODUCTION}

From the studies of two previous contracts with U.S. Department of Energy (DOE) (DE-AC2281 PC30019 \& DE-AC22-85PC80007), it has been concluded that the Liquid Phase Methanol $\left(\mathrm{LPMEOH}^{*}\right)$ process prefers the slurry mode of operation employing a powder catalyst. As another option, the ebullated (liquid-fluidized) mode of operation requires a granular or pelletized catalyst. The attempt to identify a viable catalyst to withstand the vigorous turbulence in an ebullated reactor has not been successful.(1) In addition, the granular or pelletized catalyst, relatively large in size, showed significant pore diffusion resistance, which limited the overall rate of methanol formation. In contrast, the slurry opei ation uses a micron sized powder catalyst with minimal pore diffusion resistance, which should benefit the rate of methanol reaction.

In April 1987, Air Products and Chemicals, Inc. began the current contract with DOE to finalize the development of the LPMEOH process. At the beginning of the contract, only one bona-fide powder catalyst had been successfully tested in the Process Development Unit (PDU) at LaPorte, Texas. The project team felt that it was strategically important to identify at least one other commercially available catalyst for the L.PMEOH process. Hence, a research goal of the current contract was to identify at least one alternative slurry catalyst for the process. Two tasks were established in the current contract to achieve this goal. Under Task 3.6, commercially available methanol catalysts in powder form were to be screened for their methanol activity and slurry properties. One promising candidate was to be advanced for a laboratory 40-day life test under Task 3.7.

A successful catalyst candidate for slurry reactors requires not only acceptable intrinsic activity but also acceptable slurry properties. Specifically, the desirable slurry properties are 1) low fouling tendency, 2) low slurry viscosity, and 3) relatively low catalyst porosity given acceptable intrinsic activity. Low fouling tendency alleviates potential equipment fouling problems. Lower slurry viscosity allows easier movement of the slurry and enhances the mass transfer rate in a slurry reactor. Lower catalyst porosity, while maintaining intrinsic activity, will permit more catalyst by weight in a fixed reactor volume to increase the volumetric productivity of the reactor. Maintaining intrinsic activity can be achieved via a catalyst design with more pores and/or better dispersion of active metals on the catalyst.

\footnotetext{
*A trademark.
} 


\section{OBJECTIVES}

The objective of Task 3.6 was to identify at least one alternative commercially available methanol catalyst in powder form for the LPMEOH process. Representative samples of viable methanol catalysts, before pelletizing, were obtained for evaluations. The scope of work required that three such commercial catalysts be tested. The criteria for choosing an acceptable catalyst were 1) comparable or better activity than the standard catalyst, and 2) reasonable rheological properties when slurried in a recommended mineral oil. A promising candidate was then selected for a 40-day life test in a lab autoclave under Task 3.7 before a demonstration in the LaPorte PDU.

\section{PATENT SITUATION}

From the slurry property investigations, a catalyst with smaller pore volume showed better slurriability. Catalysts with smaller porosity can also increase the volumetric productivity of a reactor, given catalyst activity per unit mass stays constant. U.S. Patent $\# 4,910,227$, "High Volumetric Production of Methanol in a Liquid Phase Reactor," was awarded by the U.S. Patent and Trademark Office in March 1990.

\section{SAFETY}

All the experimental work was conducted in a $300 \mathrm{cc}$ autoclave at Air Products' Iron Run facilities. All safety issues were properly addressed according to Air Products safety guidelines and documented in the Hazards Review dated 17 March 1988. 


\section{RESULTS AND DISCUSSION}

\section{A. Selection of Commercial Catalysts}

Among catalyst properties, Loss-on-Ignition (LOI) of a methanol catalyst was found to be related to catalyst fouling tendency in the LPMEOH process. . $^{(2,3)}$ Tests conducted at the Fairfield lab PDU by Chem Systems (2) showed serious equipment fouling by a powder catalyst. Postmortem catalyst analyses by Air Products suggested that LOI was one measurement that correlated with fouling tendency. Other properties investigated included particle size distribution, porosity, density, BET surface area, and impurities on catalyst.

In a later study, ${ }^{(3)}$ the effect of LOI on catalyst activation was examined. Activation of a catalyst with $6.5 \%$ LOI showed poor results. The study concluded that the catalyst LOI should be greater than or equal to $11 \%$.

LOI measures the amount of volatile matter on a catalyst. It is determined as the percent weight loss by heating a catalyst sample under $\mathrm{N}_{2}$ flow at $760^{\circ} \mathrm{C}\left(1,400^{\circ} \mathrm{F}\right)$ for two hours. For the $\mathrm{Cu} / \mathrm{ZnO} / \mathrm{Al}_{2} \mathrm{O}_{3}$ methanol catalysts, in addition to physically adsorbed water, $\mathrm{LOI}$ indicates the weight fraction contributed from chemically bonded water and $\mathrm{CO}_{2}$ in the form of hydroxyl carbonates. Catalyst composition affects LOI as does the history of heat treatment of the catalyst.

The exact reason why LOI correlates well with fouling tendencies is unclear. However, the following speculation seems to be reasonable. During catalyst activation, both water vapor and $\mathrm{CO}_{2}$ gas evolve from the catalyst. Catalysts with higher LOI generate a larger quantity of vapors. It can be speculated that the amount of vapors emitted during catalyst activation causes certain pore structures to form, which influences catalyst fouling tendency.

According to the scope-of-work of the current contract, three commercially available catalysts were obtained. Table 1 lists these catalysts and compares their LOI numbers and nominal compositions with those of the standard catalyst. These samples were taken at various stages from their regular manufacturing process before pelletizing. The catalyst designations which were used in the DOE reports are also shown in Table 1 . Table $1 \mathrm{~A}$ identifies each catalyst by its manufacturer and code. This information is proprietary and is subject to the restriction appearing on the title page of this report.

\begin{tabular}{|lcccc|}
\hline \multicolumn{5}{c|}{ Table 1 } \\
\multicolumn{4}{|c|}{ Loss-on-Ignition and Nominal Composition of Methanol Catalysts } \\
& F21/0E75-44 & F21/0E75-43 & F51/0E75-38 & F51/0E75-40 \\
\hline LOI, wt\% & 11.5 & 14.5 & 13.9 & 20.5 \\
Nominal Comp., wt\% & & & & \\
CuO & 41.8 & 68 & 60 & 60 \\
ZnO & 54.6 & 26 & 30 & 30 \\
$\mathrm{Al}_{2} \mathrm{O}_{3}$ & 3.8 & 6.0 & 10 & 10 \\
\hline
\end{tabular}




\section{Table 1A}

CATALYST IDENTIFICATION FOR TASK 3.6/3.7

\begin{tabular}{|lll|} 
Catalyst Code & Manufacturer & Comments \\
\hline F21/0E75-35 & BASF & S3-85 powder, earlier batch for lab testings \\
F21/0E75-43 & BASF & S3-86 powder used in LaPorte Runs E-6 through E-9 \\
F21/0E75-44 & BASF & S3-85 powder used in LaPorte Run E-3 \\
F51/0E75-27 & ICI & Precursor for 51-2 catalyst; so called "ICI Black" powder \\
F51/0E75-38 & ICI & 51-2 catalyst powder with mild heat treating (LOI $=13.9 \%)$ \\
F51/0E75-40 & ICI & 51-2 catalyst powder with mild heat treating (LOI $=20.5 \%)$ \\
F51/0E75-81 & ICI & $\begin{array}{l}\text { Earlier version of } 51-2 \text { catalyst; so called "ICI Green" } \\
\text { powder }\end{array}$ \\
& &
\end{tabular}

\section{B. Catalyst Activity Test in Lab Autoclave}

All activity screening tests were conducted in a $300 \mathrm{cc}$ autoclave with a $35 \mathrm{wt} \%$ catalyst slurry. The slurry was prepared with 66 grams of respective catalyst (as received) and approximately 122.5 grams of Freezene 100 or Witco 70 oil. After activation in-situ following the procedure described in a recent patent, ${ }^{(4)}$ the catalyst was subjected to $\mathrm{CO}$-rich gas for activity measurement. The CO-rich gas, which simulates unshifted clean coal gas from a Texaco gasifier, has a nominal gas composition of $51 \% \mathrm{CO}, 35 \% \mathrm{H}_{2}, 13 \% \mathrm{CO}_{2}$, and $1 \% \mathrm{~N}_{2}$. The test conditions were $250^{\circ} \mathrm{C}$ temperature and 750 psig system pressure. The feed gas rate was varied to give at least two space velocity points for each catalyst. Each activity screening experiment ran continuously for about 10 days.

Figure 1 depicts the results and comparison with the performance curve of the standard catalyst. All these data were taken after 24 hours on syngas to exclude "hyperactivity." As shown in Figure 1, all three candidates show better activity than the standard catalyst. To further distinguish these candidates, other properties such slurry viscosities of these catalysts in mineral oils were measured and are discussed subsequently in Sections $C$ through F. 


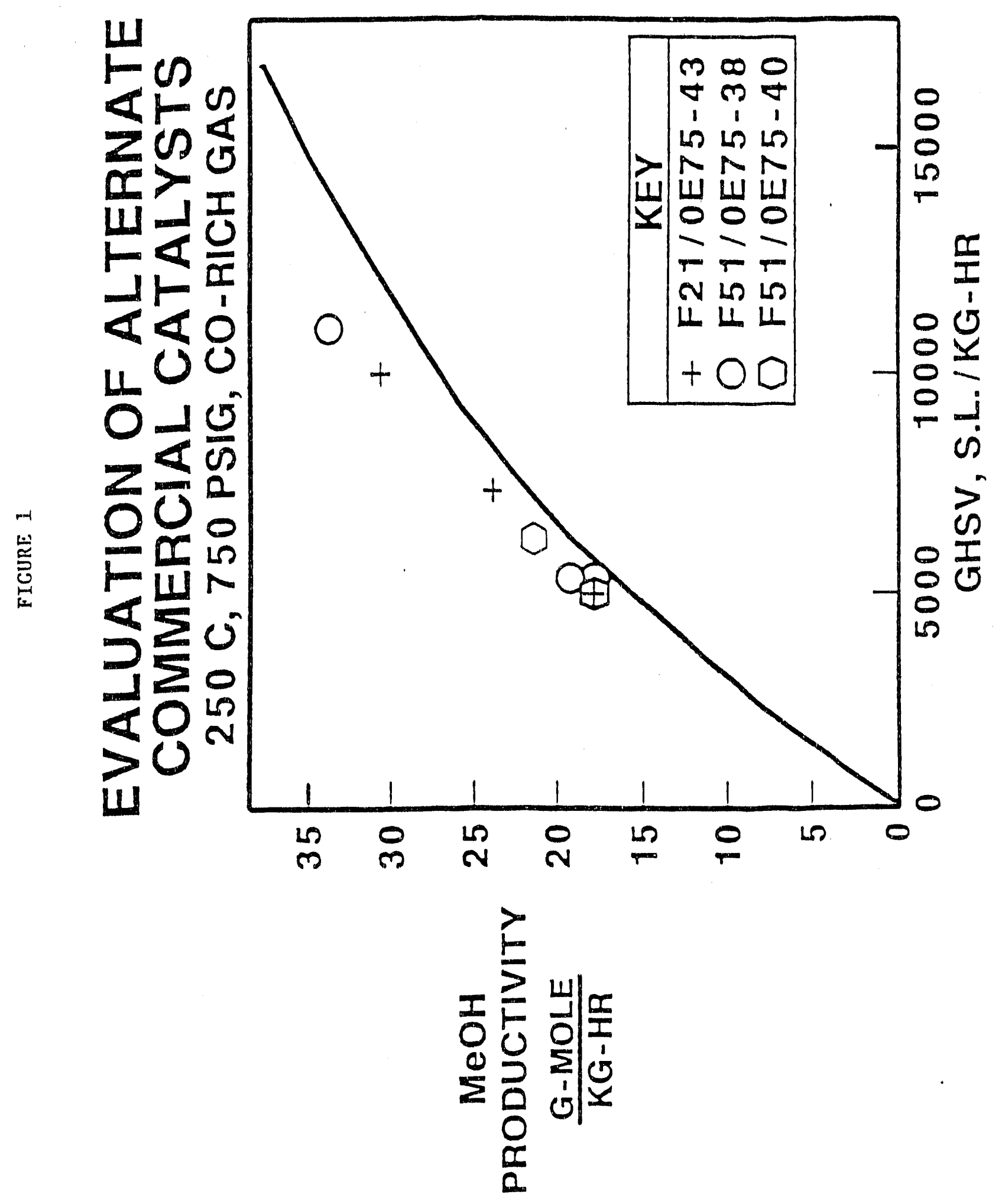




\section{Measurement of Slurry Viscosity}

Slurry viscosity is one of the key parameters that governs the rheological behavior of the slurry. Lower viscosity is desirable for easier movement and better heat transfer rate of the slurry. In addition, lower viscosity can enhance the mass transfer rate ${ }^{(5,6)}$ in a slurry reactor to improve reactor performance.

Slurry viscosities were measured using a Haake rotating viscometer with an MV III viscometer head. Witco 70 was used as the slurrying liquid. In addition to the three catalyst candidates, the standard catalyst was also measured for its viscosity in the mineral oil. In this study, all viscosities were measured at the same weight loading of $35 \mathrm{wt} \%$ catalyst, since the catalyst activity and other economic factors are based on the catalyst weight. Figures $2 \mathrm{a}$ through $2 \mathrm{~d}$ summarize the relationship between viscosity, eta, and shear rate, $\mathrm{D}$, at $25^{\circ} \mathrm{C}$. All slurry samples showed viscosity decreases with increasing shear rate, suggesting "shear thinning" effect. Catalyst F21/0E75-43 slurry showed the lowest viscosity at all shear rates up to $4.5 / \mathrm{sec}$.

\section{Batch Sedimentation Tests}

Batch sedimentation tests show the collective effect of particle properties such as size, density, shape and orientation, and interference from neighboring particles. Fluid viscosity and density also affect the sedimentation rate. ${ }^{(7)}$ The sedimentation test procedure used in this study is detailed in the Appendix. In a typical batch sedimentation, suspended particles settle by gravity and generate two zones, a clear supernatant layer with minimal solids concentration and a sludge layer with a high concentration of solids. As sedimentation proceeds, the supernatant layer becomes larger at the expense of the sludge layer. Eventually, the sludge layer settles to a fixed volume called the ultimate volume that is invariant with time.

In addition to the three candidates and the standard catalyst, two other catalysts, F51/0E75-81 and F51/0E75-27, were tested for their sedimentation behavior. The results are presented in Table 2 and further depicted in Figure 3. Catalyst F51/0E75-81 was at one time the preferred catalyst for the LPMEOH process. However, before the catalyst could be tested in the lab PDU, the manufacturing process was changed and the catalyst became unavailable. Hence, its successor, F51/0E75-27, was tested in the Fairfield PDU. Serious fouling was observed various process equipments, including heat exchangers. ${ }^{(1)}$ One key property difference between these two catalysts was the LOI.

The sedimentation test is only a qualitative measure of "slurriability" and the results suggest that F21/0E75-43 has the best slurry properties. Catalyst F51/0E75-27 (a bad slurry catalyst from Fairfield PDU experience) showed the slowest settling rate and resulted in the loosest packing. On the other hand, cataly'st F21/0E75-35 (a good slurry catalyst), which was successfully tested in the LaPorte PDU, demonstrated much faster settling rate and smaller ultimate volume. The above results imply that fast settling rate and smaller ultimate volume are the preferred properties. Smaller ultimate volume is also desirable from a view point of improving volumetric productivity. It allows more catalys $i$ (on a weight basis) to be loaded into a fixed reactor volume to produce more methanol. 


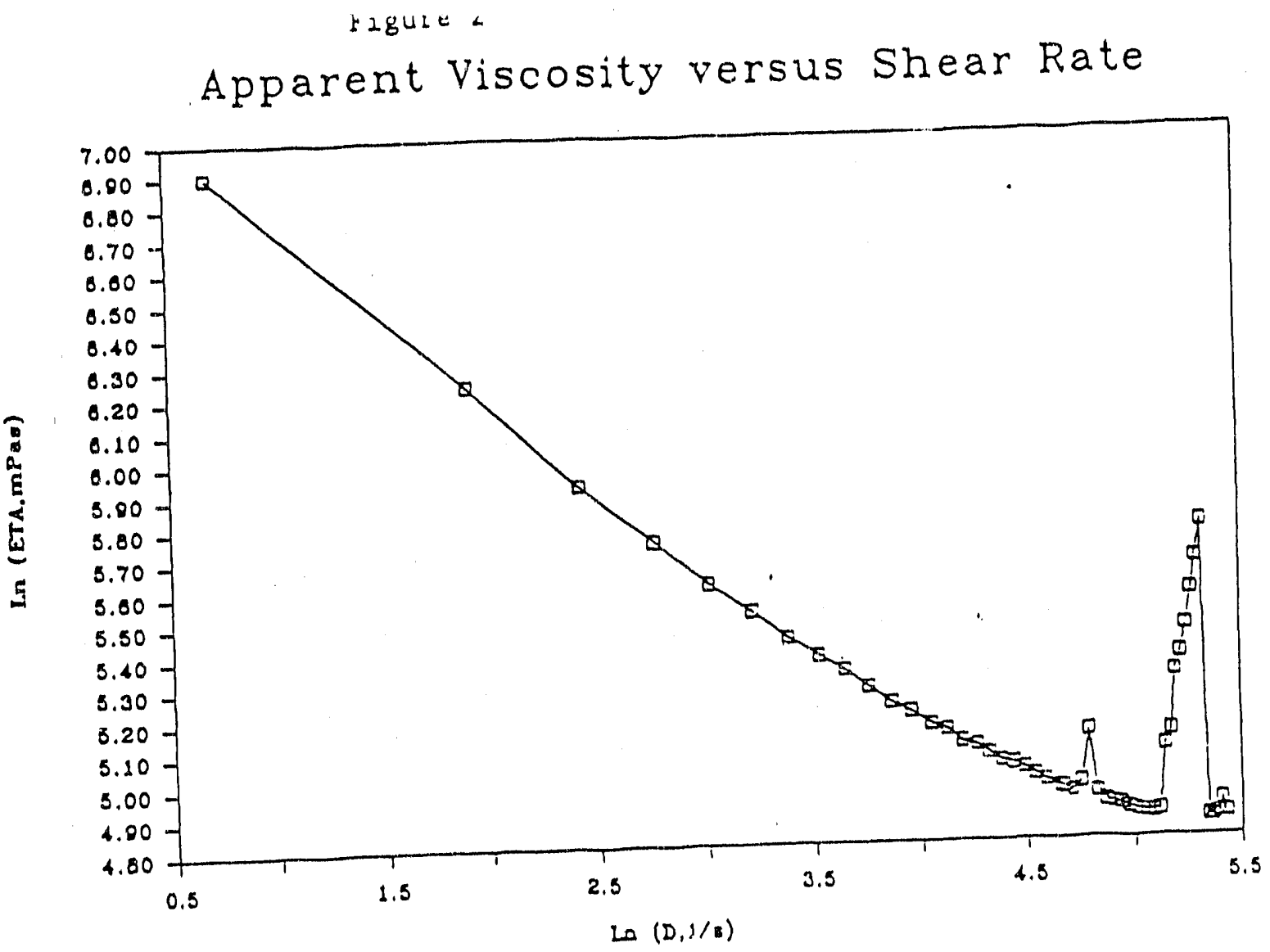

a. F21/OE75-44 in Witco 70,35 wt\%

Apparent Viscosity Versus Shear Rate

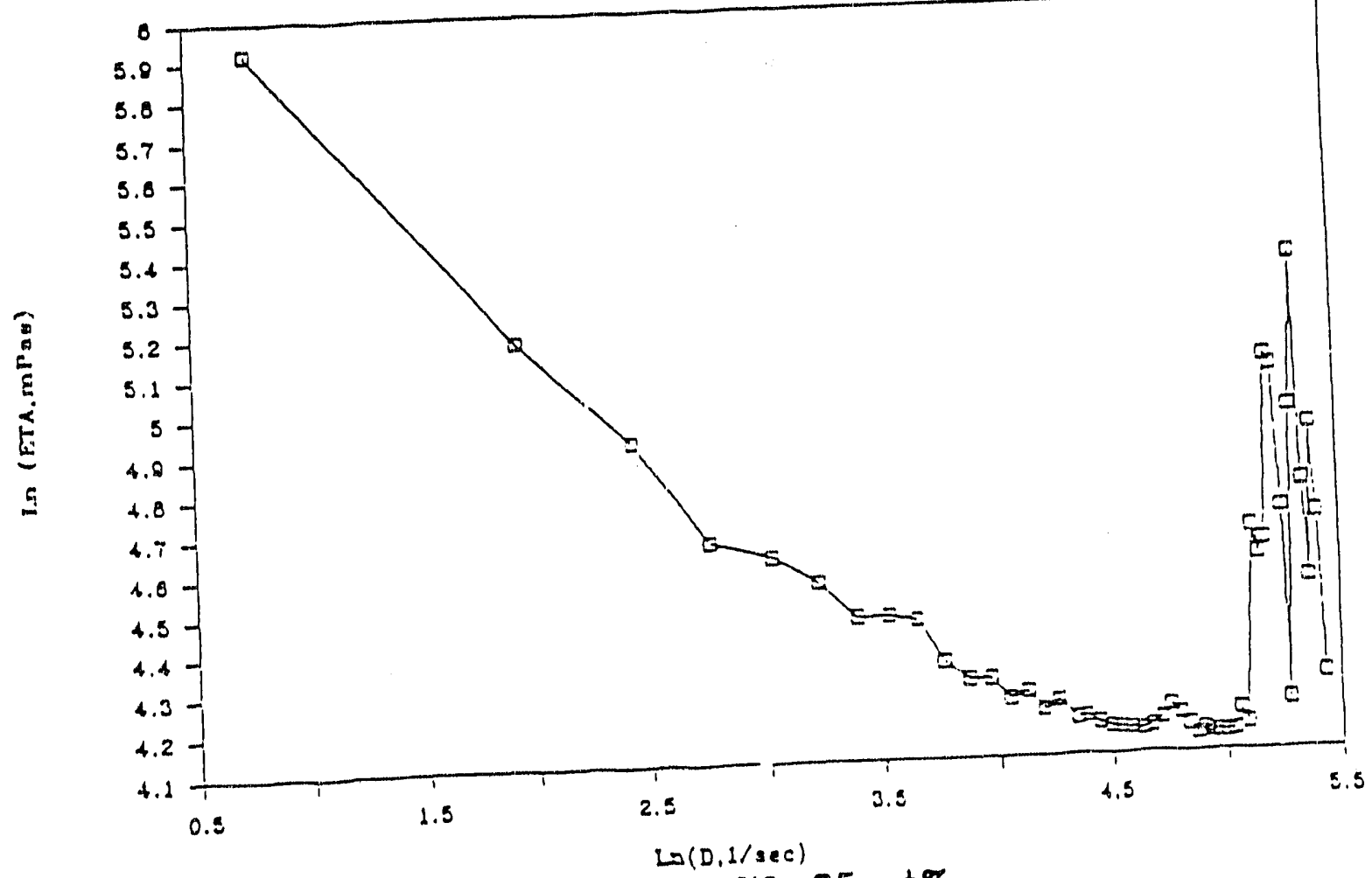

b. F21/OE75-43 in Witco 70,35 wt\% 
Apparent Viscosity versus Shear Rate

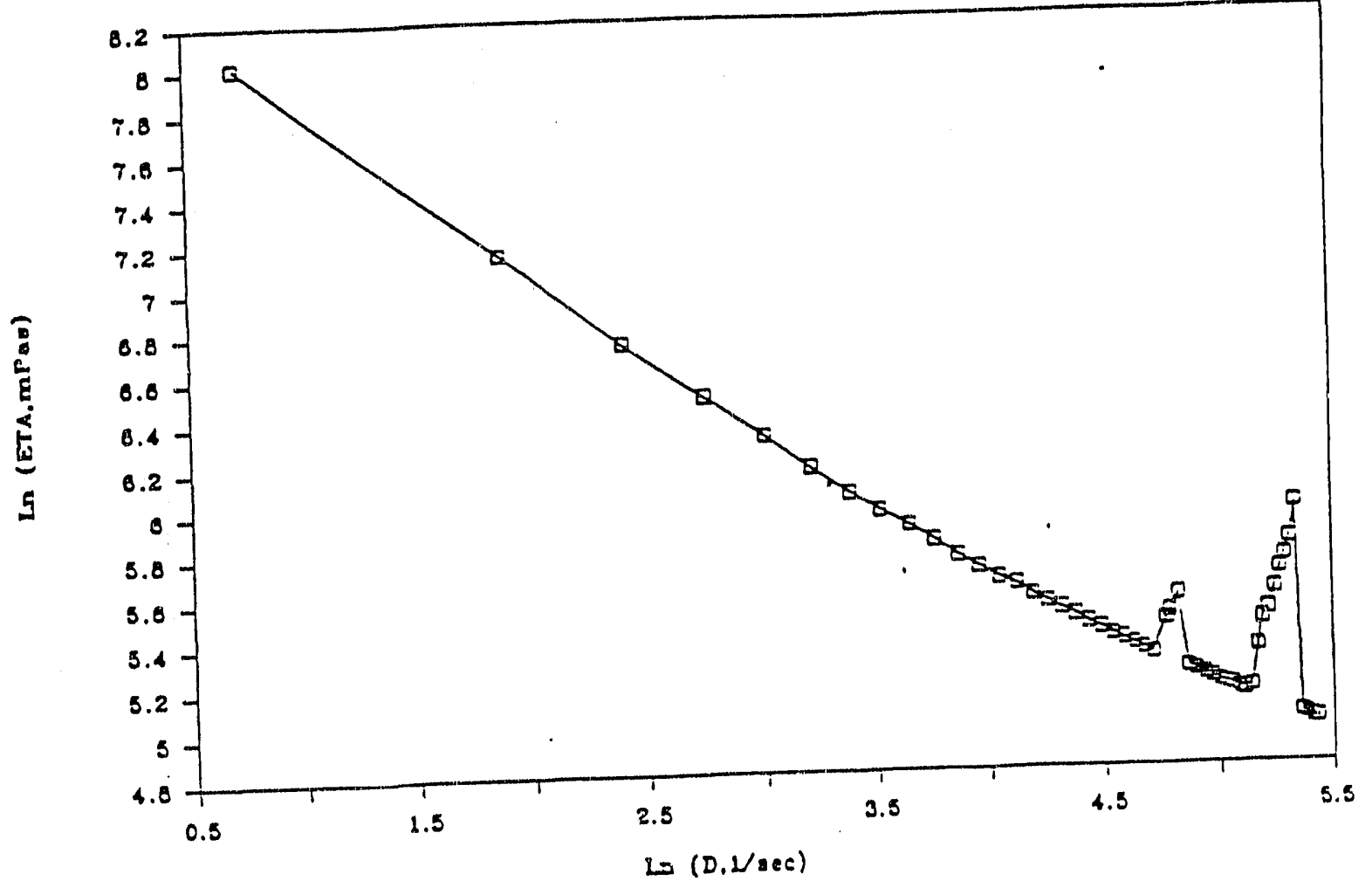

c. F51/OE75-38 in Witco 70, 35 wt\%

Apparent Viscosity versus Shear Rate

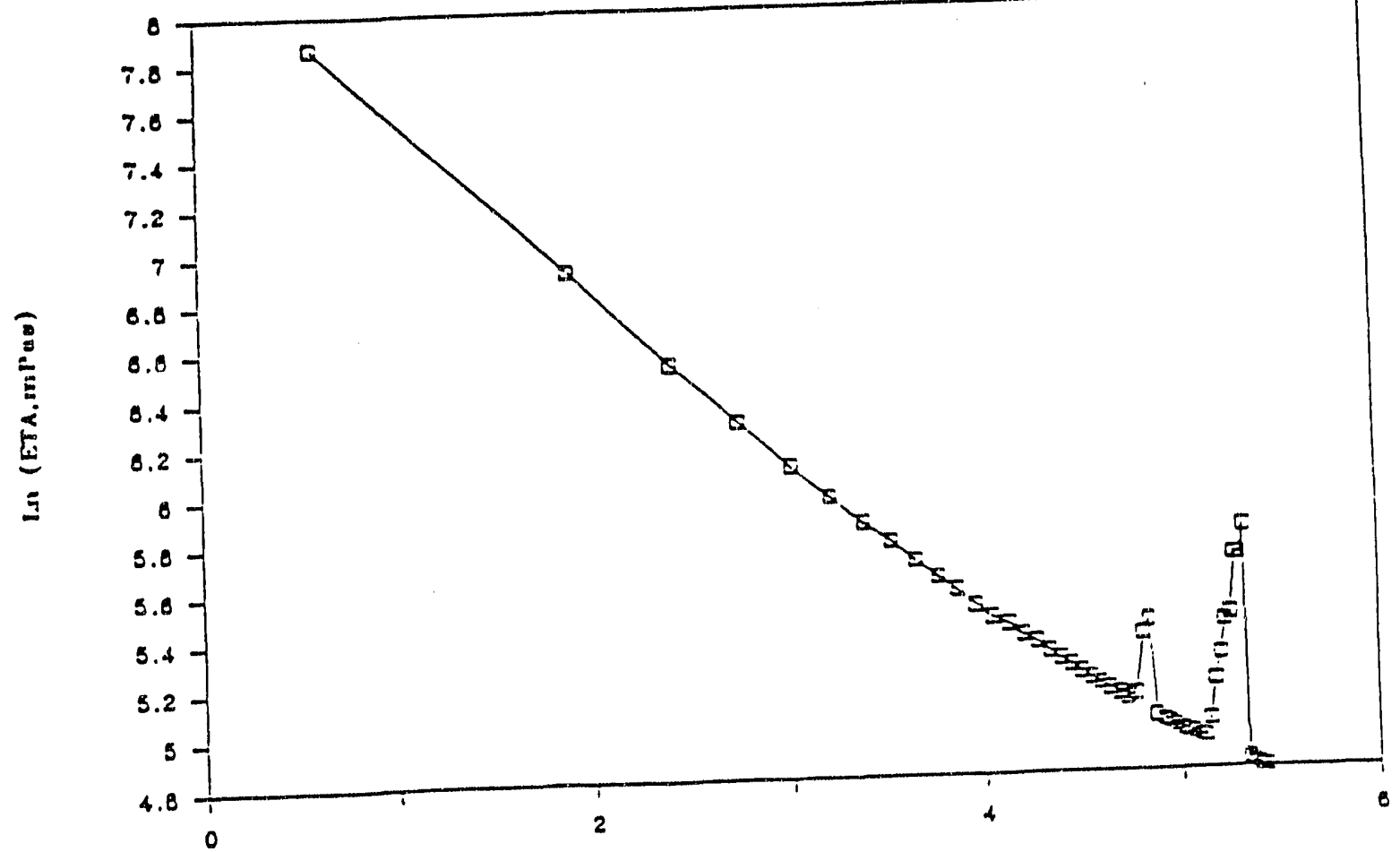

Lo $(D, 1 / \mathbf{0})$

d. F51/OE75-40 in Witco 70, 35 wt\% 


\section{TABLE 2}

\section{SEDIMENTATION TEST OF METHANOL CATALYSTS IN WITCO 70 MINERAL OIL.}

(19 Grams of Catalyst in 77.85 Grams of Witco 70 Oil)

Volume of Slurry, ml

Time, $\min$ F21/OE75-35 F21/0E75-44 F21/0E75-43 F51/0E75-38 F51/0E75-40 F51/0E75-81 F51/0E75-77

\begin{tabular}{|c|c|c|c|c|c|c|c|}
\hline 0 & 95 & 95 & 95 & 97 & 97 & 97 & 97 \\
\hline 15 & 64 & 73 & 61 & 89 & 89 & 94 & 93 \\
\hline 30 & 43 & 54 & 38 & 82 & 82 & 91 & 91 \\
\hline 45 & 38 & 46 & 33 & 72 & 77 & 87 & 89 \\
\hline 60 & 37 & 37 & 28 & 69 & 73 & 85 & 88 \\
\hline 75 & 36 & 36 & 28 & 66 & 71 & 83 & 86 \\
\hline 90 & 36 & 36 & 28 & 64 & - & & 85 \\
\hline 95 & & - & . & . & 68 & 81 & - \\
\hline 105 & & 35 & & 63 & - & $\therefore$ & \\
\hline 115 & & - & - & . & 66 & 80 & \\
\hline 120 & & 35 & & 61 & . & - & \\
\hline 135 & & & & 60 & 64 & 78 & \\
\hline 150 & & & & 59 & 63 & 77 & \\
\hline 165 & & & & 58 & - & - & \\
\hline 175 & & & & . & 61 & 76 & \\
\hline 180 & & & & 58 & & . & \\
\hline 195 & & & & & 60 & 75 & \\
\hline 215 & & & & & 59 & 74 & \\
\hline$>17.5 \mathrm{hrs}$ & 36 & 35 & 28 & 45 & 45 & 58 & 60 \\
\hline
\end{tabular}

Repetition Experiment:

0
10
15
20
25
30
40
67
127

$\begin{array}{ll}95 & 95 \\ 78 & 69 \\ 71 & 58 \\ 65 & 48 \\ 59 & 40 \\ 54 & 37 \\ 47 & 33 \\ 40 & 29 \\ 36 & 28\end{array}$

18 hrs.

35

28 


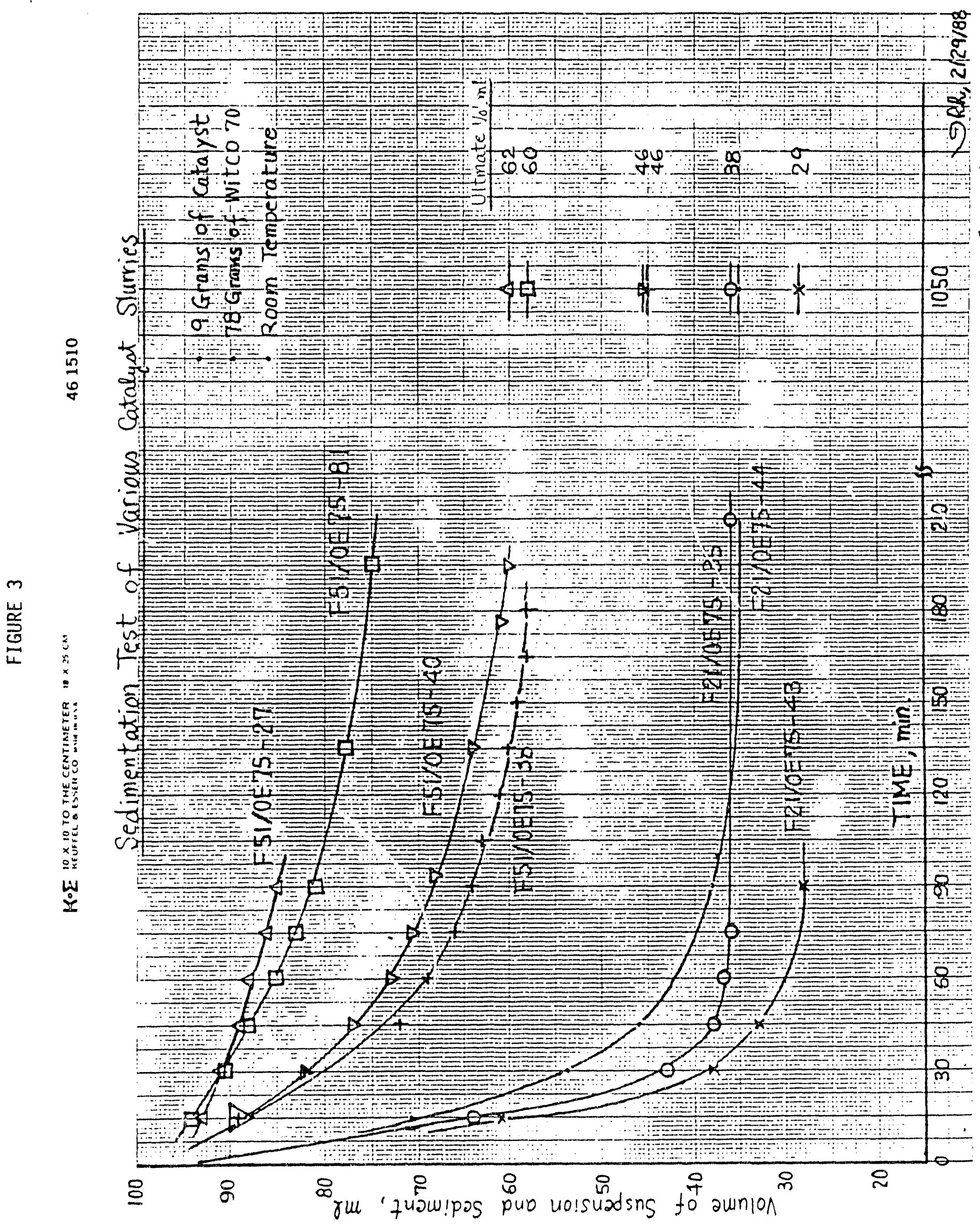




\section{E. Comparison of Catalyst Properties}

In addition to the slurry characteristics, other properties were measured for these catalyst candidates. Table 3 tabulates the results. The pore volume data shown in Table 3 confirms the potential of F21/ 0E75-43 being a more productive catalyst. This catalyst shows the lowest pore volume among all the catalysts tested. Since all three candidates exhibited comparable methanol synthesis activity based on per unit mass of catalyst, the catalyst with the lowest pore volume would be the most desirable. Lower pore volume allows more catalyst by weight to $b i s$ loaded in a fixed reactor volume, and better reactor productivity is resulted.

Based on the data shown in this table, F21/0E75-43 exhibited the most desirable properties in every aspect. Hence, F21/0E75-43 was recommended as a potential alternate catalyst to be advanced for a life test.

\section{F. Further Comparison of Properties between F21/0E75-43 and F21/0E75- 44 Catalyst}

Additional properties were obtained on the new F21/0E75-43 catalyst. Table 4 compares these properties with the equivalent of the standard F21/0E75-44 catalyst. The skeletal density and the weight loss in $\mathrm{H}_{2}$ of the new catalyst a , higher than standard catalyst. After catalyst activation (reduction), the copper crystallite size on the new catalyst is slightly higher, however, the $\mathrm{ZnO}$ crystallite size is smaller. All these differences are probably associated with higher copper content on F21/0E75-43.

Thermo Gravinetric Analysis (TGA) can determine the content of volatile matters of a methanol catalyst. When hydrogen is used, the TGA result, along with the LOI numbers, generates information on the copper content on the catalyst. Figures 4 and 5 show the TGA results for F21/ 0E75-43 and F21/0E75-44 catalyst, respectively. From these figures, both catalysts have moisture contents of 4.5 to $5.0 \mathrm{wt} \%$. The weight loss after hydrogen reduction is $18.7 \mathrm{wt} \%$ for F21/0E75-44 and $25.9 \mathrm{wt} \%$ for F21/0E75-43, suggesting that the latter has a higher $\mathrm{CuO}$ content. These weight loss values are about 5 to $10 \%$ higher than their respective values obtained in a gas phase reduction unit after a standard catalyst reduction routine. This comparison implies that the copper is not entirely reduced to its metallic state after the activation scheme, which agrees with the results of Herman, et al. ${ }^{(8)}$

\section{G. Activity Maintenance of Catalyst F21/0E75-43 in Autoclave}

Since the F21/0E75-43 catalyst showed most promising properties, it was tested in the $300 \mathrm{cc}$ autoclave for activity maintenance. The scope-of-work for Task 3.7 demands at least a 40-day life test. A $15 \mathrm{wt} \%$ slurry, which is made by mixing 25 grams of catalyst and 142 grams of Drakeol 10 mineral oil, was activated in-situ to begin the life test. The reactor conditions were set at $250^{\circ} \mathrm{C}$ temperature and 750 psig system pressure. CO-rich gas was used and the feed gas space velocity was set at $5400 \mathrm{sl} / \mathrm{hr} / \mathrm{kg}$-catalyst. 


\section{Table 3}

\section{Physical Properties of Methanol Catalysts}

F21/OE75-44 F21/0E75-43 F51/0E75-38 F51/0E75-40 F51/0E75-27

$\mathrm{BET}, \mathrm{m}^{2} / \mathrm{gm}$

Pore Vol., cc/gm

Skeletal (He) Density, $\mathrm{g} / \mathrm{cc}$

Viscosity, MPaS*

Settling Rate, $\mathrm{cc} / \mathrm{min}^{* *}$

Ultimate Vol., cc

@ 20 wt\% Slurry
84.6

0.785

4.21

136

2.07

38
87.4

0.588

4.55

64

2.27

29
103

1.17

4.47
70

0.988

3.81
104

$-$

--

*Apparent viscusity of 35 wt\% slurry @ $25^{\circ} \mathrm{C}$ and $100 / \mathrm{sec}$ shear rate

** Initial settling rate of $20 \mathrm{wt} \%$ slurry in Witco $70 @$ room temperature

\section{TABLE 4}

Comparison of F21/0E75-43 and F21/0E75-44 Catalyst Properties

A. Oxide Catalyst (as received)

LOI, wt. \%

$\mathrm{BET}, \mathrm{m}^{2} / \mathrm{gm}$

Pore Vol., cc/gm

He Density, gm/cc

Wt. Loss in $\mathrm{H}_{2}$ TGA, \%

B. Reduced Catalyst

$\mathrm{Cu}$ Crystallite, Angstrom

$\mathrm{ZnO}$ Crystallite, Angtrom

BET Area, $\mathrm{m}^{2} / \mathrm{gm}$

He Density, gm/cc
14.5

87.4

0.588

4.55

25.9

11.5

84.6

0.785

4.21

18.7 


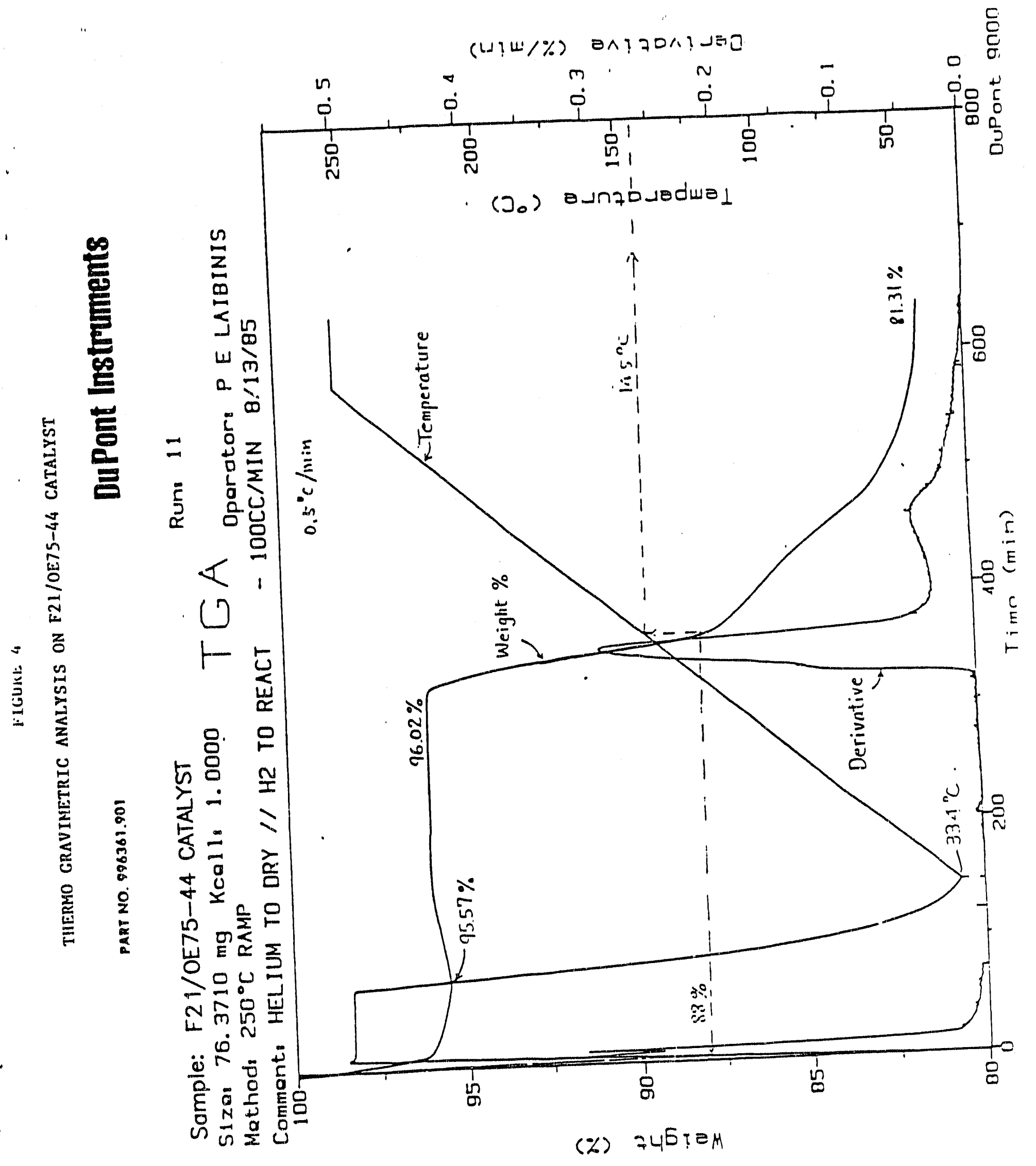




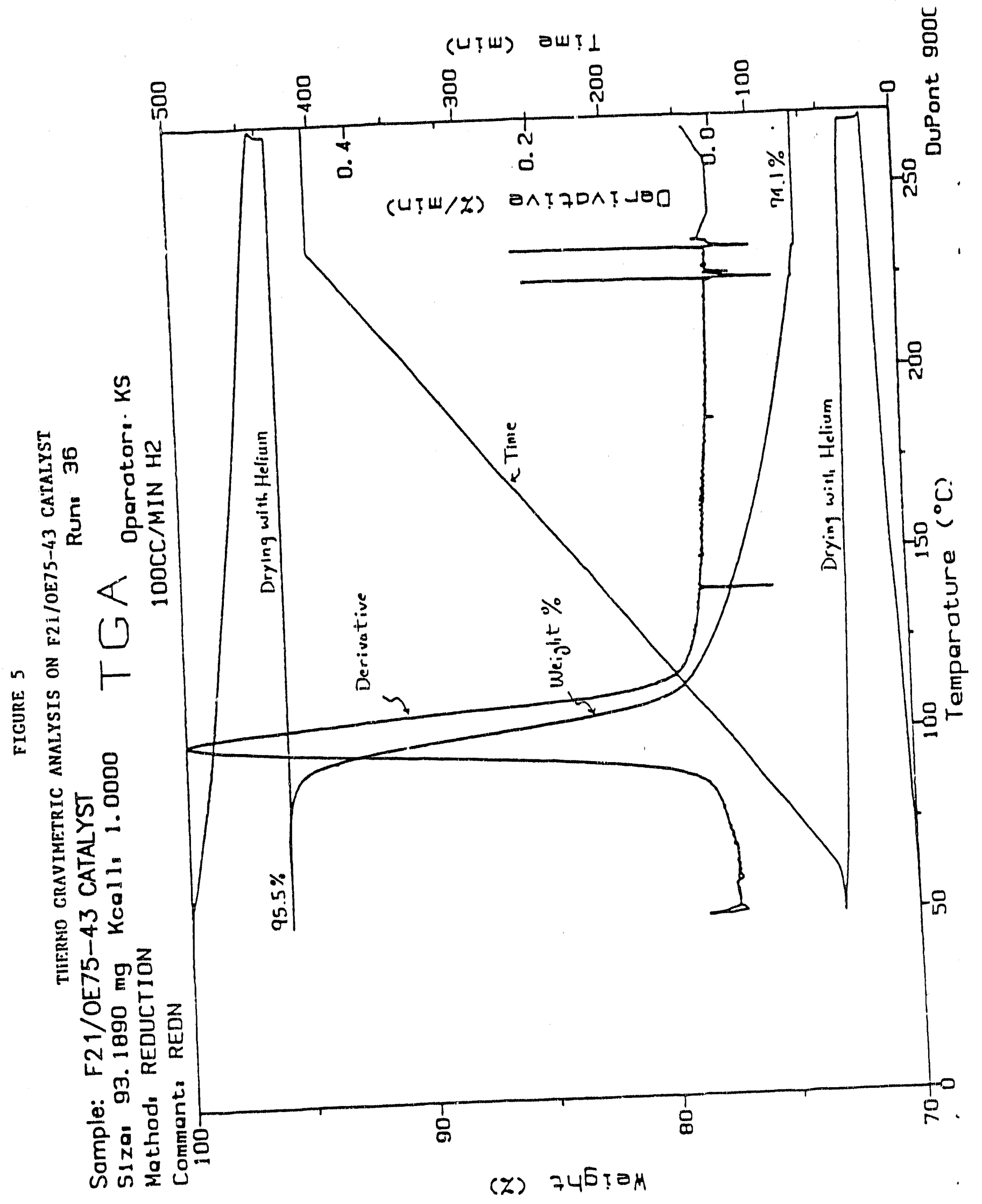


The 40-day life test results are summarized in Figure 6. Both methanol productivity and exit methanol concentration were plotted against time on synthesis gas. Due to serious GC problems, the early activity data are not available. However, consistent and frequent data were obtained after 575 hours on-stream. A total continuous run time of 1050 hours has achieved.

Compared with the lab life test result on the standard F21/0E75-44 catalyst, this new catalyst demonstrated superior stability. As shown in Figure 6, the decline of methanol productivity (and exit methanol concentration) with time seems to be leveling off. Using the data obtained after 600 hours on-stream, a specific deactivation rate of 0.0016 productivity units per hour is estimated. This is based on a worst-case linear deactivation model. This rate of decline translates into about $0.19 \%$ relative productivity loss per day. The equivalent deactivation rate for the standard catalyst had been determined in earlier work ${ }^{(3)}$ to be 0.0024 productivity units per hour or $0.38 \%$ productivity loss per day. ${ }^{(3)}$ The latter activity maintenance data (for the standard catalyst) were obtained at a lower space velocity condition, ${ }^{(3)}$ hence they are not included in Figure 6 as direct comparison is confusing.

A sample of the end-of-run catalys! was analyzed for $\mathrm{Cu}$ and $\mathrm{ZnO}$ crystallice sizes by $\mathrm{X}$-ray diffraction. Moderate growth was noted on both $\mathrm{Cu}$ and $\mathrm{ZnO}$ as shown in Table 5, confirming stability of the catalyst.

\section{Table 5 \\ XRD Results on F21/0E75-43 Catalyst}
Run \#
I.D.
Hrs. on Gas
$\mathrm{Cu}+\mathrm{O}, \AA$
$\mathrm{ZnO}, \AA$

Fresh Catalyst F21/0E75-43

9397-36-EOR F21/0E75-43

0
1050

Catalyst F21/0E75-43 is concluded to be acceptable for the LPMEOH process and recommended for demonstration in the PDU at LaPorte, Texas. 


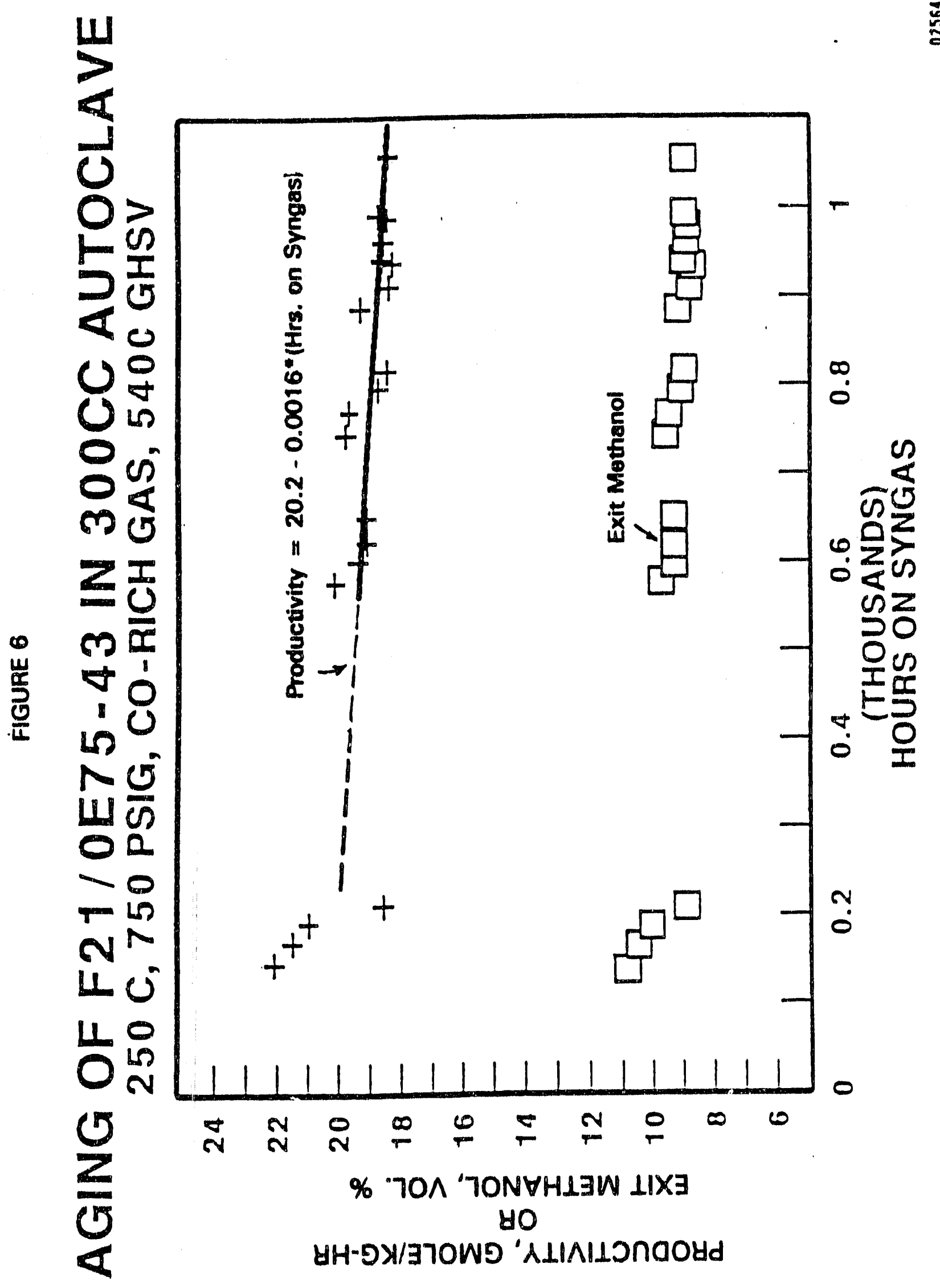




\section{SUMMARY AND CONCLUSIONS}

Among the three commercial catalysts evaluated, the new F21/0E75-43 low temperature methanol catalyst (in powder form before pelletization) is recommended as the alternative catalyst. This catalyst not only demonstrated approximately $10 \%$ higher activity than the standard F21/0E75-44 catalyst, but also showed lower slurry viscosity in the slurrying liquid. In addition, the catalyst has lower pore volume than the standard catalyst so it has the potential to yield higher productivity for a given reactor volume. Based on these results, this catalyst was advanced ror a life test in the lab autoclave.

A 40-day life test in the lab autoclave on F21/0E75-43 catalyst showed superior stability when compared with that of the standard F21/0E75-44 catalyst. A linear deactivation rate of $0.19 \%$ per day on methanul productivity has been estimated. This rate of activity decline compares favorably against the decline rate of $0.41 \%$ established on the standard catalyst. This slower catalyst deactivation was further substantiated by the crystallite size analysis by $\mathrm{X}$-ray diffraction, as slower copper crystal size growth was observed.

After these qualification tests, the F21/0E75-43 catalyst was recommended for the LaPorte PDU program under the current DOE contract. 


\section{REFERENCES}

1. "Evaluation of R71/0F12-02 Catalyst in the CSI Liquid -Fluidized Process Development Unit," Topical report by Chem Systems Inc. to DOE as a subcontractor to Air Products and Chemicals, Inc., July 1982.

2. "Liquid Phase Methanol Process Development Unit Installation, Operation, and Support Studies," Topical Report to DOE, Chem Systems Inc., September 1984.

3. "Liquid Phase Methanol Process Development Unit: LaPorte PDU Research and Engineering Studies," Final Report on DOE Contract No. DE-AC-85PC90007, Air Products and Chemicals, Inc., February 1988.

4. "In-Situ Activation of $\mathrm{CuO} / \mathrm{ZnO} / \mathrm{Al}_{2} \mathrm{O}_{3}$ Catalysts in the Liquid Phase," U.S. Patent \#4801574.

5. Capuder, E., and T. Koloini, "Gas Hold-Up and Interfacial Area in Aerated Suspensions of Small Particles," Chem. Eng. Res. Des., Vol. 62, 255 (1984).

6. Schumpe, A., A. K. Saxena, and L. K. Fang, "Gas/Liquid Mass Transfer in a Slurry Bubble Column," Chem. Eng. Sci., Vol. 42, No. 7, 1787 (1987).

7. "Solid-Liquid Separation," L. Svarovsky, ed., Chapter 5, published by Butterworths, 1977.

8. Herman, R. G., K. Klier, G. W. Simmons, B. P. Finn, J. B. Bulko, and T. P. Kobylinski, "Catalytic Synthesis of Methanol from CO/H2," J. of Catalysis, Vol. 56, 407-429 (1979). 


\section{APPENDIX}

\section{Experimental Procedure of Sedimentation Test}

1. Weigh 77.85 grams of Freezene 100 into a $100 \mathrm{cc}$ graduated cylinder.

2. Add 19 grams of catalyst to the oil.

3. Seal the opening with a sheet of plastic seal.

4. Shake the graduated cylinder until the catalyst and oil are well mixed.

5. Set the graduated cylinder on a flat lab bench top and immediately start a timer.

6. Observe the slurry interphase and record the slurry volume every five minutes. The time interval can be extended when the settlement slows down.

7. Record the final settled slurry volume. 

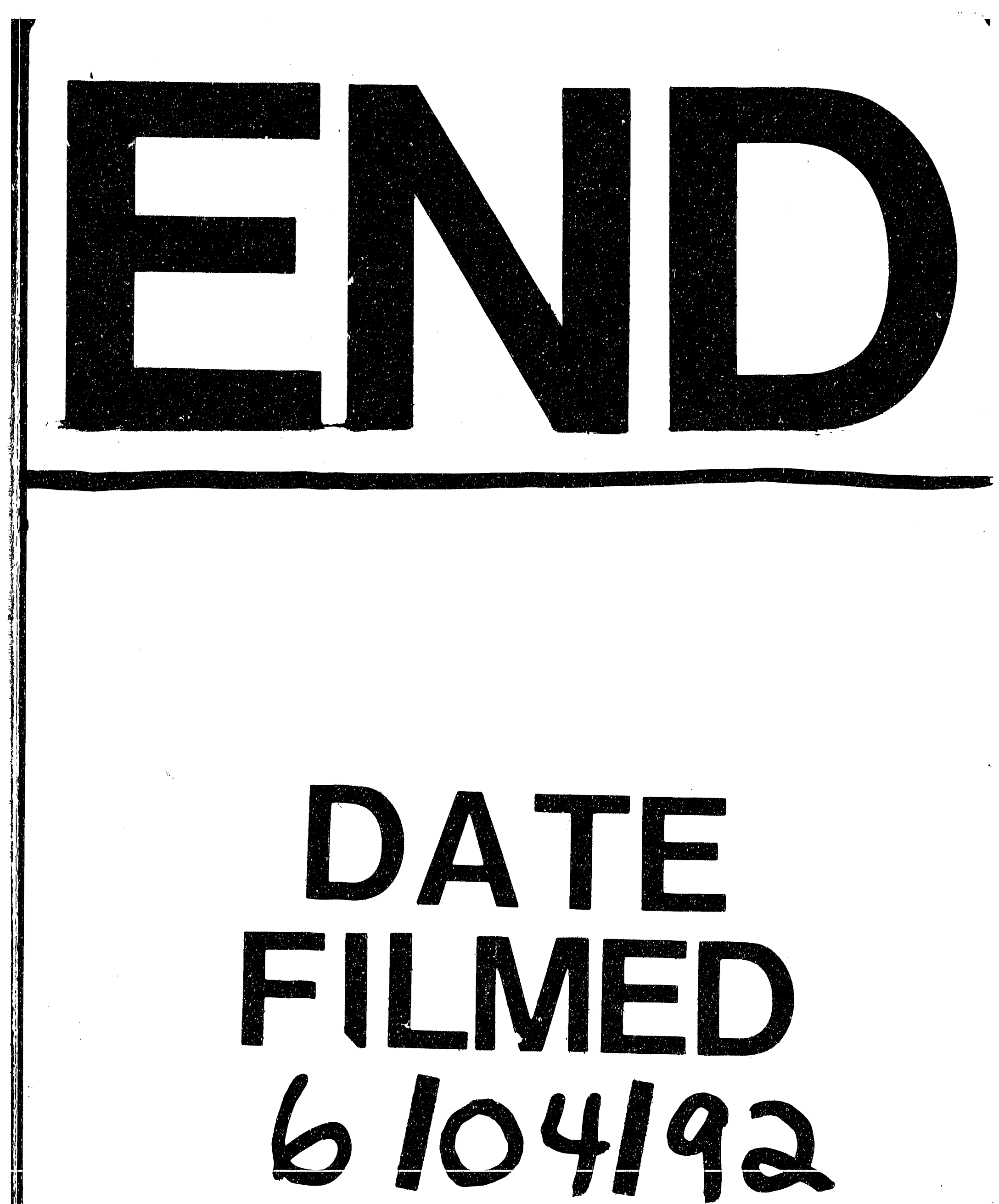
